\title{
Study on Liquid Phase Hydrogenation Technology of White Oil
}

\author{
Tiezhen Zhang*, Famin Sun, Yungang Jia, Fangming Xie, Fucun Wang, Haiyan Li, Zijin Yan, Wei Jiang \\ Petrochina Daqing Petrochemical Research Center, Daqing, Heilongjiang, 163714, China \\ Email: zhangtz4590petrochina.com.cn
}

\begin{abstract}
Using Aspen Plus simulation software to simulate the hydrogen solubility of white oil raw materials, and calculate the de-aromatic hydrogen consumption. The liquid hydrogenation technology of white oil was studied by using $100 \mathrm{~mL}$ uplink liquid hydrogenation evaluation device. The research results show that the ultraviolet absorbance of the liquid phase hydrogenation product is no more than 0.1 , and saybolt color, copper plate corrosion, readily carbonizable substance can meet the quality requirements under the conditions of $230^{\circ} \mathrm{C}, 17 \mathrm{Mpa}$ and LHSV $0.5 \mathrm{~h}^{-1} .2000$ hours liquid phase hydrogenation test shows the stability of product quality which meets the food grade standard, and the liquid phase hydrogenation technology is feasible.
\end{abstract}

Keywords: white oil, hydrogen solubility simulation, liquid phase hydrogenation, process research, catalyst

\section{Introduction}

The traditional hydrogenation process uses trickle bed hydrogenation, which is a mature and reliable technology and is widely industrialized in oil refinery hydrogenation units ${ }^{[1]}$. However, the trickle bed technology still has some shortcomings in the following aspects: (1) low catalyst utilization efficiency; (2) High material consumption and energy consumption of the device; (3) High operating costs. By contrast, liquid phase hydrogenation technology can dissolve hydrogen in the raw oil to meet the hydrogen need for hydrogenation reaction, so as to cancel the traditional hydrogen circulation system. All feeds are reacted in liquid phase in the reactor, which do not need hydrogen transfer. The hydrogen needed in hydrogenation reaction is dissolved enough through the liquid circulation ${ }^{[2]}$. Liquid phase hydrogenation technology can overcome the shortcomings of traditional trickle bed hydrogenation technology. It don't need hydrogen circulation system, and have the characteristics of safe operation, simple process, brief control, less process equipment and less occupation of area, which is especially suitable for saturation of aromatic hydrocarbons in deep hydrogenation of white oil and some other low hydrogen consumption chemical reactions.

The core of liquid hydrogenation technology is the dissolved hydrogen needed in hydrogenation reaction of raw materials ${ }^{[3]}$, and the solubility of hydrogen in oil is one of the key issues of liquid hydrogenation technology. However, the research on the solubility of hydrogen in petroleum under high temperature and high pressure are relatively scarce. Therefore, study on the solubility of hydrogen in white oil is of great significance, which can provides a basis for the index determination of liquid phase hydrogenation process.

In this study, the solubility of hydrogen in oil was measured by simulation method, and the liquid hydrogenation technology was test by using a $100 \mathrm{~mL}$ uplink liquid hydrogenation evaluation device.

\section{Determination of Hydrogen Solubility in White Oil}

\subsection{Establishment of Simulation Flow Chart}

The simulation software Aspen Plus was used to establish the process simulation of the separator, and the basic steps of the steady state simulation process were as follows: selecting modules $\rightarrow$ connecting feeds $\rightarrow$ defining components $\rightarrow$ inputting feeds data $\rightarrow$ selecting physical property methods $\rightarrow$ inputting module parameters $\rightarrow$ running programs. Figure 1 shows the flow chart of gas solubility simulation calculated by Aspen. 


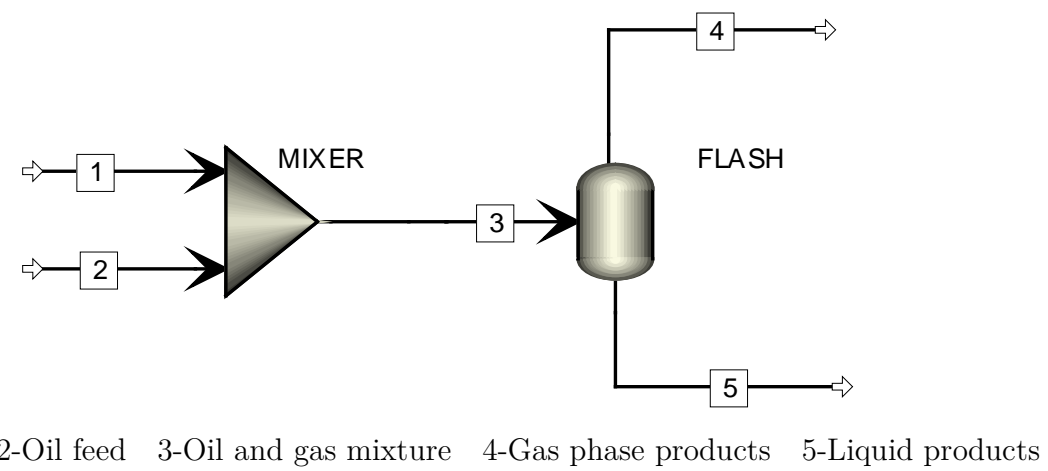

Figure 1. Flow chart of Aspen simulation calculation of gas solubility

\subsection{Basic Data Input}

The properties of the white oil raw material are shown in Table 1.

Table 1. Properties of white oil raw material used in simulation

\begin{tabular}{llcc}
\hline Items & & Data & Analysis method \\
\hline Density $\left(20^{\circ} \mathrm{C}\right), \mathrm{g} / \mathrm{cm}^{3}$ & & 0.8842 & GB/T 1884-2000 \\
\hline & $\mathrm{HK} / 10 \%$ & $380.0 / 413.0$ & \\
Distillation range, ${ }^{\circ} \mathrm{C}$ & $30 \% / 50 \%$ & $433.0 / 450.0$ & ASTM D86 \\
& $70 \% / 90 \%$ & $468.0 / 493.0$ & \\
\hline Saybolt color, number & $95 \% / \mathrm{KK}$ & $504.0 / 518.0$ & GB/T 3555 \\
\hline & $275 \mathrm{~nm}$ & +26 & \\
Ultraviolet absorbance & $295 \mathrm{~nm}$ & 1.813 & SHT 0415 \\
& $305 \mathrm{~nm}$ & 0.363 & \\
\hline Hydrocarbon & Alkanes & 0.335 & SHT 0606 \\
composition, wt $\%$ & $\mathrm{Cycloparaffins}$ & 7.1 & \\
\hline nitrogen content, $\mu \mathrm{g} / \mathrm{g}$ & Aromatics & 92.5 & ASTM D5762 \\
sulphur content, $\mu \mathrm{g} / \mathrm{g}$ & & 0.4 & SHT 0689 \\
Kinematic viscosity $\left(40^{\circ} \mathrm{C}\right), \mathrm{mm}^{2} / \mathrm{s}$ & 1.10 & ASTM D445 \\
Kinematic viscosity $\left(100^{\circ} \mathrm{C}\right), \mathrm{mm}^{2} / \mathrm{s}$ & 0.81 & ASTM D445 \\
Readily carbonizable substance & 114.8 & GB/T 11079 \\
\hline
\end{tabular}

\subsection{Simulation Calculation of Hydrogen Dissol-Ution in White Oil}

The solubility of hydrogen changes with the change of temperature and pressure was simulated by Aspen Plus, and the results were shown in Figure 2.

It can be seen from Fig. 2 that the saturated solubility of hydrogen in white oil increases with the increase of temperature and pressure. When the pressure is $17.0 \mathrm{MPa}$ and the temperature is $230^{\circ} \mathrm{C}$, the saturated solubility of hydrogen is $1040 \mu \mathrm{g} / \mathrm{g}$. In the process of hydrogenation of white oil, increasing the reaction temperature and pressure is beneficial to dissolve the hydrogen in white oil.

\subsection{Hydrogen Consumption of White Oil Hydrodearomatization}

In view of the complexity of the specific molecular composition of white oil feed, according to the total aromatics content of $0.4 \mathrm{wt} \%$, the average molecular structure of aromatics is estimated to be benzoanthracene from the distillation range of raw oil, and the complete hydrogenation saturation consumes about 9 molecules of hydrogen. Therefore, the hydrogen consumption of hydrodearomatization 
of white oil is estimated to be $0.028-0.034 \mathrm{wt} \%$. Under the conditions of operating pressure $17.0 \mathrm{MPa}$ and reaction temperature $230^{\circ} \mathrm{C}$, the theoretical amount of dissolved hydrogen is $0.104 \mathrm{wt} \%$, which can meet the demand of hydrogen in the whole liquid phase hydrodearomatization reaction.

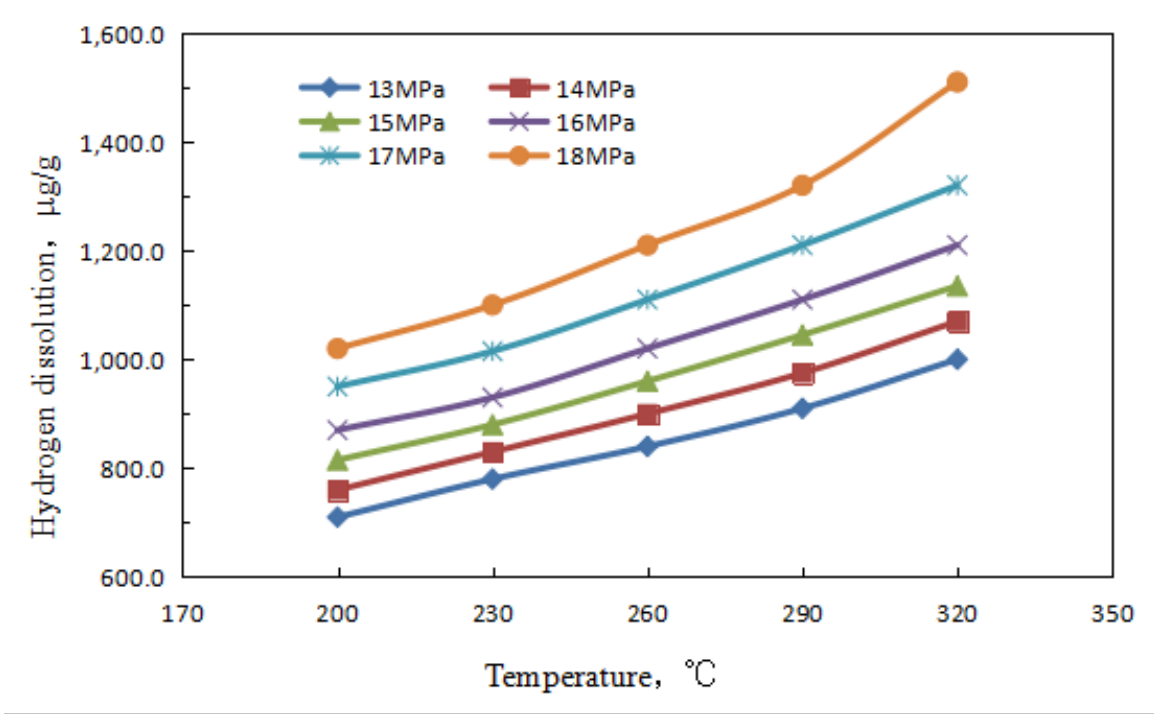

Figure 2. Simulation calculation results of hydrogen dissolution in white oil

\section{Study on Liquid Phase Hydrogenation Technology of White Oil}

\subsection{The Test Device}

The research of white oil liquid phase hydrogenation technology was carried out on 100ml up-flow liquid phase hydrogenation evaluation device, which is shown in Figure 3.

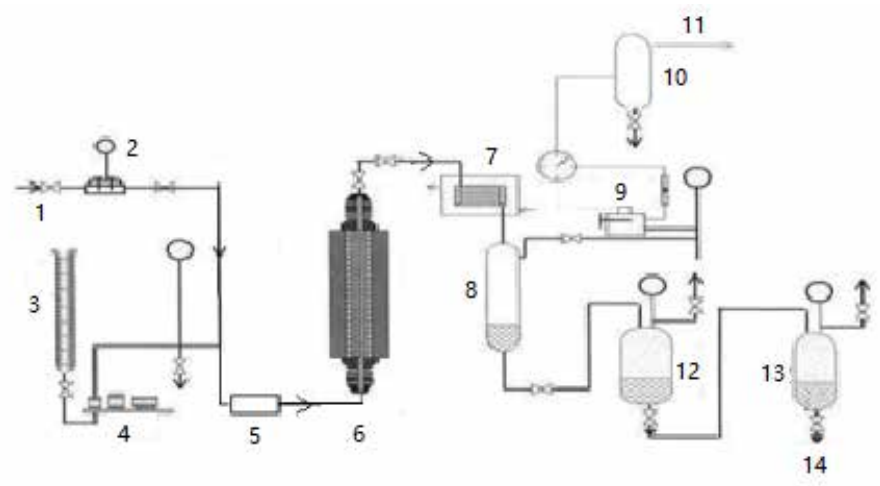

1-High-pressure hydrogen 2-Pressure governor 3-Metering Tube 4-Feed pump 5.Oil-gas mixer 6-Reactor 7-Cooler 8-High pressure separator 9-Pressure governor 10-Buffer tank 11-Tail gas 12-Low pressure separator 13-Product tank 14-Sampling port

Figure 3. Flow diagram of $100 \mathrm{~mL}$ up-flow evaluation equipment for liquid phase hydrogenation

\subsection{Source and Composition of Hydrogen}

The hydrogen used in the test is industrial hydrogen from the First Chemical Plant of Daqing Petrochemical Company, and its composition is shown in Table 2. 
Table 2. Analysis of hydrogen composition for the test

\begin{tabular}{ccccccc}
\hline Composition & $\mathrm{H}_{2}$ & $\mathrm{CH}_{4}$ & $\mathrm{C}_{2} \mathrm{H}_{6}$ & $\mathrm{CO}$ & $\mathrm{N}_{2}$ & analytical method \\
\hline Content, $\phi \%$ & 96.300 & 1.909 & 0.002 & 0.002 & 1.787 & gas chromatographic method \\
\hline
\end{tabular}

\subsection{Physical and Chemical Properties of Catalysts}

The physical and chemical properties of the catalyst including composition, specific surface area, packing density, shape and strength were analyzed. The results are shown in Table 3.

Table 3. Physical and chemical properties of white oil hydrogenation catalyst

\begin{tabular}{ccc}
\hline Items & Analysis data & Analysis method \\
\hline Catalyst shape & Clover & Visual \\
Packing density, Kg/l & 0.48 & GB/T 6286 \\
Specific surface area, $\mathrm{m}^{2} / \mathrm{g}$ & 260 & $\mathrm{~GB} / \mathrm{T} 19587$ \\
Radial crushing strength, N/cm & 144 & $\mathrm{HG} / \mathrm{T} 2782$ \\
$\mathrm{Pt}+\mathrm{Pd}$ content, wt $\%$ & 0.52 & $\mathrm{SH} / \mathrm{T} 0346$ \\
\hline
\end{tabular}

\subsection{Catalyst Loading and Reduction}

The white oil hydrogenation catalyst was loaded into the reactor by natural loading method.

Catalyst reduction conditions:

1) The system pressure was adjusted to $1.0 \mathrm{MPa}$ at a speed of $1.0 \mathrm{MPa} / 10 \mathrm{~min}$;

2) Hydrogen flow was set at $200 \mathrm{~L} / \mathrm{h}$;

3) The temperature was heated to $150^{\circ} \mathrm{C}$ at a rate of $40^{\circ} \mathrm{C} / \mathrm{h}$, and maintained for $4 \mathrm{~h}$;

4) The temperature was raised to $250^{\circ} \mathrm{C}$ at a rate of $20^{\circ} \mathrm{C} / \mathrm{h}$ and maintained for $4 \mathrm{~h}$;

5) The temperature was raised to $320^{\circ} \mathrm{C}$ at a rate of $20^{\circ} \mathrm{C} / \mathrm{h}$, and maintained for $8 \mathrm{~h}$;

6) The reactor is cooled to $220^{\circ} \mathrm{C}$, and the system pressure is increased to $17.0 \mathrm{MPa}$ at a rate of $1.0 \mathrm{MPa} / 10 \mathrm{~min}$, and then start to carry out liquid phase hydrogenation evaluation conditions.

\subsection{Evaluation Results of Liquid Hydrogenation of White Oil}

Table 4. Evaluation results of liquid hydrogenation of white oil

\begin{tabular}{|c|c|c|c|c|c|c|c|}
\hline \multicolumn{2}{|c|}{ Items } & \multirow[t]{2}{*}{ Raw material } & \multicolumn{5}{|c|}{ Products } \\
\hline \multicolumn{2}{|c|}{ Process conditions } & & Cond. 1 & Cond. 2 & Cond. 3 & Cond. 4 & Cond. 5 \\
\hline \multicolumn{3}{|c|}{ Pressure, MPa } & 17 & 17 & 17 & 17 & 17 \\
\hline \multicolumn{3}{|c|}{ Reaction temperature, ${ }^{\circ} \mathrm{C}$} & 220 & 230 & 240 & 250 & 230 \\
\hline \multicolumn{3}{|c|}{ LHSV, $\mathrm{h}^{-1}$} & 0.5 & 0.5 & 0.5 & 0.5 & 1 \\
\hline \multicolumn{2}{|c|}{ Density $\left(20^{\circ} \mathrm{C}\right), \mathrm{g} / \mathrm{cm}^{3}$} & 0.8842 & 0.8854 & 0.8854 & 0.8853 & 0.8853 & 0.8854 \\
\hline \multicolumn{2}{|c|}{ Saybolt color, number } & 26 & 30 & 30 & 30 & 30 & 30 \\
\hline \multirow{3}{*}{$\begin{array}{l}\text { Ultraviolet } \\
\text { absorbance }\end{array}$} & $275 \mathrm{~nm}$ & 1.813 & 0.106 & 0.075 & 0.045 & 0.039 & 0.124 \\
\hline & $295 \mathrm{~nm}$ & 0.363 & 0.064 & 0.043 & 0.043 & 0.041 & 0.086 \\
\hline & $305 \mathrm{~nm}$ & 0.335 & 0.048 & 0.042 & 0.041 & 0.038 & 0.063 \\
\hline \multicolumn{2}{|c|}{ nitrogen content, mg/g } & 1.1 & $<0.5$ & $<0.5$ & $<0.5$ & $<0.5$ & $<0.5$ \\
\hline \multicolumn{2}{|c|}{ sulphur content, $\mathrm{mg} / \mathrm{g}$} & 0.81 & $<0.5$ & $<0.5$ & $<0.5$ & $<0.5$ & $<0.5$ \\
\hline \multicolumn{2}{|c|}{ Copper plate corrosion $\left(100^{\circ} \mathrm{C}, 3 \mathrm{~h}\right)$} & $3 a$ & $1 b$ & 1a & $1 \mathrm{a}$ & $1 \mathrm{a}$ & $1 \mathrm{~b}$ \\
\hline \multicolumn{2}{|c|}{ Readily carbonizable substance } & Not pass & Pass & Pass & Pass & Pass & Pass \\
\hline
\end{tabular}

Table 4 evaluation results show that, under the pressure of $17 \mathrm{MPa}$, LHSV of $0.5 \mathrm{~h}^{-1}$, reaction temperature of $230^{\circ} \mathrm{C}$, the UV absorbance of liquid hydrogenation products is no more than 0.1 , and all indexes can meet the quality requirements of food grade white oil. With the increase of reaction temperature, the UV 
absorbance of liquid hydrogenation products was gradually decreased. The dissolved hydrogen in white oil can meet the demand of white oil hydrogenation, and the liquid phase hydrogenation process can be used in the processing of food grade white oil.

\subsection{0h Stability Test of Liquid Hydrogenation of White Oil}

Under the conditions of reaction temperature $230^{\circ} \mathrm{C}$, reaction pressure $17.0 \mathrm{MPa}$ and space velocity $0.5 \mathrm{~h}^{-1}$, the performance stability test of liquid hydrogenation of white oil had been carried out for 2000 hours. The test results are shown in Table 5.

Table 5. 2000hour stability test results of liquid hydrogenation of white oil

\begin{tabular}{|c|c|c|c|c|c|c|c|}
\hline \multicolumn{2}{|c|}{ Time, h } & 100 & 400 & 800 & 1200 & 1600 & 2000 \\
\hline \multicolumn{2}{|c|}{ Saybolt color, number } & +30 & +30 & +30 & +30 & +30 & +30 \\
\hline \multirow{3}{*}{$\begin{array}{l}\text { Ultraviolet } \\
\text { absorbance }\end{array}$} & $275 \mathrm{~nm}$ & 0.044 & 0.045 & 0.047 & 0.046 & 0.045 & 0.046 \\
\hline & $295 \mathrm{~nm}$ & 0.042 & 0.043 & 0.043 & 0.043 & 0.042 & 0.044 \\
\hline & $305 \mathrm{~nm}$ & 0.041 & 0.041 & 0.042 & 0.041 & 0.042 & 0.042 \\
\hline \multirow{2}{*}{\multicolumn{2}{|c|}{$\begin{array}{l}\text { Copper plate corrosion }\left(100^{\circ} \mathrm{C}, 3 \mathrm{~h}\right) \\
\text { Readily carbonizable substance }\end{array}$}} & $1 \mathrm{a}$ & $1 \mathrm{a}$ & $1 \mathrm{a}$ & $1 \mathrm{a}$ & $1 \mathrm{a}$ & $1 \mathrm{a}$ \\
\hline & & Pass & Pass & Pass & Pass & Pass & Pass \\
\hline
\end{tabular}

In the 2000 h stability test, the device ran smoothly. As can be seen from Table 5, the properties of liquid phase hydrogenation products, such as Seyport color, copper corrosion and transfer carbide index, did not change at individually stable conditions. Ultraviolet absorbance is stable, and hydrogenation products meet the food grade white oil index requirements. White oil liquid hydrogenation technology is feasible.

\section{Conclusions}

(1) The saturation solubility of hydrogen in white oil increases with the increase of temperature and pressure. The increase of reaction temperature and pressure is conducive to the dissolution of hydrogen in oil. Hydrodearomatization of white oil is a reaction process with low hydrogen consumption. The dissolved hydrogen content of white oil can meet the demand of liquid phase hydrodearomatization for hydrogen in theory;

(2) The uplink liquid hydrogenation evaluation results of white oil show that the dissolved hydrogen content of white oil can meet the demand of white oil hydrogenation de-aromatic, under the conditions of $230^{\circ} \mathrm{C}, 17 \mathrm{MPa}$ and LHSV $0.5 \mathrm{~h}^{-1}$, liquid phase hydrogenation products can meet the quality standard of the food-grade white oil, liquid phase hydrogenation technology can be used in food-grade white oil processing.

(3) $2000 \mathrm{~h}$ stability test shows that the liquid hydrogenation process and product properties are stable, and the liquid phase hydrogenation technology of white oil is feasible.

\section{References}

1. Kaixiang Liu, Yuhong Ruan, Hao Li. Application of continuous liquid phase hydrogenation technology in diesel oil hydrofining unit[J].Petrochemical Design, 2012, 29(2):26-29.

2. Zhe Li, Jiuchang Kang, Qingwei Meng. Progress in liquid phase hydrogenation technology[J].Contemporary Chemical Industry, 2012, 41(03):292-294.

3. Shoutao Ma, Fangming Xie, Jianhui Cui, et al. Analysis of the current situation of liquid phase hydrogenation at home and abroad[J].Petrochemical Technology, 2014, 43(Supplement):63-65. 